\title{
EM NOME DO NOME REAL: JOGO LITERÁRIO, AUTOCENSURA E DEFESA DA AUTOFICÇÃO
}

IN THE NAME OF REAL NAMES: LITERARY GAME,

Willian Vieira

Universidade de São Paulo

São Paulo, SP, Brasil

ORCID 0000-0002-6456-0512

\section{Resumo}

Esse artigo investiga o papel do nome real de terceiros no jogo literário que enseja a autoficção de Christine Angot, ao cotejar seus romances com correspondências, notas e manuscritos a eles ligados, depostos no Fonds Christine Angot, no IMEC, França. A partir da análise da evoluçáo dos nomes nos textos e do que dizem a autora e a narradora, dentro e fora do romance, sobre tal uso, pensa-se uma ontologia do nome real no literário - em comparaçáo, por exemplo, com Zola e a defesa do naturalismo. Questiona-se ainda, no nível da recepção, o efeito que tem o nome real identificável e sua defesa para a leitura do romance.

Palavras-chave: autoficção, jogo literário, censura, autocensura, ontologia literária.

\section{Abstract}

This article analyses the role of real names in the literary game performed by Christine Angot's autofictional novels. The originals are confronted with letters, notes and printed versions of the novels, found at the Fonds Christine Angot, IMEC, France. From the analysis of the evolution of the names in the different versions of the novels, and from the statements made both from the author and its homonymic narrator, inside and outside the novels, the article proposes an ontology of the use of real names in contemporary autofiction. The text also compares the defense of this right to use

\section{Résumé}

Cet article analyse le rôle du nom réel de tiers dans le jeu littéraire de l'autofiction de Christine Angot. Une comparaison est effectuée entre ses romans et les correspondances, notes et manuscrits réunis au Fonds Christine Angot à l'IMEC. L'étude montre une l'évolution des noms dans les différents documents et versions des romans. En plus des paratextes et épitextes sur l'auteure (et la narratrice du même nom), nous proposons une ontologie de l'usage du nom réel dans la littérature - une défense du droit d'utiliser les noms réels en littérature au même titre que Zola 
real names in Angot and Zola, and raises the question of how the use of real names (and its defense) impacts reception.

Keywords: autofiction, literary game, censorship, self-censorship, literary ontology il y a plus d'un siècle. Enfin, le travail s'interroge sur l'effet du nom réel dans la lecture et la réception du roman.

Mots-clés : autofiction, jeu littéraire, censure, autocensure, ontologie littérair

Les Petits, c'est une ouvre. Cette fois-ci, les prénoms des enfants ont été changés. Les traits et les détails prêtés à l'héroïne des Petits peuvent être ceux de milliers de femmes. Oui, madame la présidente, c'est vrai, on y cite un rapport du juge aux affaires familiales. C'est que Christine Angot, comme Zola, décrit la réalité .

Como Zola, pai do naturalismo, Christine Angot, rainha da autoficção, "descreve a realidade", declamou o advogado da escritora diante do juiz que a condenaria, em 2013, a pagar 40 mil euros por "atentado à vida privada" - por ter usado a vida de pessoas reais em seu romance. "Dessa vez, os nomes das crianças foram modificados", disse. A frase não foi o suficiente para convencer o juiz, mas enseja o debate mais frutífero em torno da literatura de Angot e da autoficção, espécie de corrente maldita da literatura contemporânea. Por que enfrentar os críticos, a opiniáo pública e a justiça - em nome do nome real em literatura?

A citação do advogado não é em vão. Para compreender o jogo literário de Angot, deve-se voltar ao século XIX, quando Zola enfrentava seu tribunal. A peroração teórico-crítica do escritor e a que faz Angot, mais de um século depois, nas cortes, na imprensa ou nos romances, realizam o mesmo tipo de defesa ontológica da literatura. Central para tal defesa, jaz o nome próprio; e não o da homonímia autoral, já gasta e previsível, mas o de terceiros, ainda vivos, opondo liberdade de expressão e ética do fazer literário e seu impacto no mundo.

1 Obtido em <http://www.lexpress.fr/culture/livre/proces-christine-angot-a-t-elle-depasse-les-limites-del-autofiction_1234607.html\#iB4b22AKmqUW6RUU.99> 
Quando Zola foi afrontado, primeiro via uma carta do diretor da revista na qual publicava seu folhetim, e logo nos tribunais, pela reclamação de certo M. Duverdy (BECKER \& LAVIELLE, 1999) que detinha o mesmo nome e identidade de um personagem seu, o escritor - justamente em nome do naturalismo que viria a defini-lo - bateu o pé. Não mudaria uma letra² ${ }^{2}$ Se retrocedesse diante da alegação, seria enorme a chance ver seus personagens ganharem na vida real quem com eles se identificassem, procurando a interdição da justiça. A censura adviria como resultado (ZOLA, 2014, p. 469).

Duas questóes se colocam: que o autor deve se submeter à performance do processo e que tal martírio público se sustenta em nome de qualquer autor em potencial que use nomes próprios para seus personagens; logo, de toda "uma literatura" - a naturalista. A autoficção de Angot, como veremos, também se arvora o direito de cravar no real o valor ontológico do nome como fonte de fruição estética, encontrando, na provocação ética, seu norte literário.

Zola fazia uso extenso da tribuna de revistas e jornais e, em último caso, de reclames que abriam seus romances, para defender sua literatura "científica". Se tivesse que fazer um detour de sua garimpagem no real, por obrigaçóes legais, explicitava-o ao leitor. A amputação de seu projeto literário, por questóes de ordens morais, éticas ou jurídicas impostas por terceiros (o editor, o juiz) era extemporânea à pureza de sua literatura, seu projeto literário ${ }^{3}$. "Or Émile Zola se plait à dire les règles du jeu”, escreve GIRAUD (2011, p. 31), partindo da noçâo de LAHIRE (2006) de jogo literário. Ele queria ditar as novas regras do campo ao tentar modificar as bases teóricas que ditam o valor da própria de horizonte da literatura.

Zola buscava um "investimento literário" (2011, p. 1) que garantisse adesão. Crítico antes de ser autor, via com olhos teóricos o jogo no qual se inseria. Escritor em busca de sobrevivência, via na literatura um metiê (2007, p. 9). Giraud pontua como Zola, já reconhecido e rico, falava de "trouver quelque sentier inexploré" (p. 30). Ao mesmo tempo, forjou as condições de existência da legitimidade que defendia. Como "un farouche entrepreneur de lui-même et de son personnage littéraire et journalistique" (idem), usou bem sua "estratégia literária". Mestre da produção, da divulgação e da recepção crítica, viu no embate com o sistema um valor em si - e uma estratégia. É na valorização do combate que Zola encontra seu "instrumento de legitimação" particular. Daí aferrar-se ao uso dos nomes reais. Ele sabia que sua literatura,

2 Em carta ao diretor, de 29 de janeiro de 1882, Zola escreve: "Vous me demandez mon opinion, au sujet du procès que nous intente $M$. Duverdy, avocat à la Cour d'appel, pour nous forcer à changer, dans le roman que j'ai écrit et que vous publiez, le nom de "Duverdy" donné par moi à un de mes personnages. Mon opinion est que nous devons nous laisser faire ce procès” (ZOLA, 2014, p. 467, grifos meus).

3 Em carta aberta no mesmo Les Gaulois, Zola dizia que precisava tomar emprestado os nomes de pessoas onde os personagens viviam para "completar pela realidade do nome a realidade da fisionomia" (BECKER \& LAVIELLE, 1999, p. 112, tradução minha). 
naturalista, dependia dessa tribuna. Quanto mais tivesse a chance de discorrer sobre sua especificidade, mais ela se confundiria com ele mesmo, mais seria tido como o autor naturalista que queria ser. Daí a importância do nome próprio retirado da realidade (fosse do velho Bottin, dos jornais ou da vida que o cercava).

É quando retornamos à autoficção. O caso de Christine Angot complexifica o de Zola na medida em que tais reclames ganham o corpo do romance, não apenas na voz da narradora, mas em intertextos que mostram ao leitor seu caráter de material do real. São trechos de críticas e resenhas, de cartas e outros romances e mesmo de documentos internos da editora. Todos assinados, com nomes reais ou, se forçados pelas mesmas forças externas (o editor, o juiz), adaptados para lembrar, de fato, o nome anterior.

Angot tampouco se furta da tribuna: mas, além do jornal e da revista, tem a seu dispor a televisão e a Internet. Suas performances num programa televisivo, numa emissão de rádio, num debate ou leitura pública - tudo ganha o próprio espaço do romance narrado em primeira pessoa homônima. Como já foi dito, "o estágio midiático se interpóe entre a pilhagem biográfica, a criação imaginativa, ficcional, e a leitura, a fruição interessada por um público voyeur" (Vieira, 2016, p. 156) 4 . Diz Angot que, para "convencer o leitor da autenticidade de todas as nossas invençóes literárias", o documento "é o meio mais garantido" (1999, p. 29). O documento real, a polêmica midiática, o jogar-se como autor na cova dos leôes da opinião pública: tudo vale, é sua performance literária. Entre a defesa conceitual da literatura e a performance necessária para provocar o embate que virá a legitimá-la como vanguarda, Angot se aferra à provocação dos limites impostas pela ética (do senso comum) ou pela justiça.

É ao se aferrar a uma defesa ontológica do direito de usar o real sem amarras, retomada do discurso naturalista de Zola, que ela se firma em sua especificidade e se constrói como escritora-personagem. Seguindo a lógica do jogo literário de Lahire, veremos como a defesa ontológica de "uma literatura" do real torna-se o próprio ensejo do literário em Angot.

L'inceste, a inauguração da estratégia de legitimação do não-limite em Angot

Primeiro romance de Angot a causar mal-estar pelo uso de nomes de terceiros, Linceste (1999) é o sexto romance da autora. Aqui, Christine (p. 12), escritora, conta como se apaixonou por uma médica e a perseguiu durante dias. Ela fala de seu editor, do pai com Alzheimer (p.13), que sua filha é Léonore (p. 16); há ainda Claude (p. 19), o ex-marido citado em obras

4 Já a justiça é uma etapa além, na qual a performance autoral vira batalha de ideias, que só vem afiançar o postulado crítico-teórico em torno da prática. Em uma escrita performática que propõe a discussão de seu próprio estatuto, artístico e legal, não há efeito bastante sem a performance mais completa possível (idem). 
anteriores. É a mesma narradora que traz a público histórias de pessoas de seu entorno mantendo os nomes reais. Logo se percebe que o que está em jogo no romance não é só um amor complicado e sim a própria ideia do que pode ser matéria de literatura.

Ma chérie, Quinze heures quinze Je suis allée promener Pitou mon coeur Je t’aime MCA. Je n'ai pas encore décidé si je l'appellerai X, anonyme, MCA ou son nom entier (p. 21).

É o jogo do dizível, dos limites, sançôes e perigos que envolvem tal literatura de tipo íntimo. Como chamar a personagem que, para o leitor, é protegida pela sigla por ser alguém real? É na provocação que jaz seu espaço de criação - e o embate da apropriação, muitas vezes indébita, de quem cerca o escritor, como se viver junto já autorizasse o uso da vida como texto: de suas histórias de vida, documentos íntimos, cartas, cadernos, telefonemas. Mas o diálogo entre o nome supostamente real, a sigla que substitui o nome e o monólogo autocrítico da autora-narradora sobre o uso do nome em sua literatura dá um passo além.

Elle semblait montrer quelque chose à X. Elle ne veut pas que je l'appelle X. Ni son vrai nom, ni ses initiales. (...) Ni X, ni MCA, ni Marie-Christine Adrey, ni Aime CA. Mon amour? Ma chérie? (p. 35).

No nível da diegese, a provocação avança na explicação da narradora: ela náo só se apropria do nome e história dos outros, mas mostra o processo de criação, mesclando vida e literatura. A narradora emenda então outra provocaçáo: um longo trecho do que parece uma carta da advogada da editora que a publica, demandando mudanças no manuscrito (procedimento comum a grandes editoras, aqui é exposto como um manifesto anticensura).

Je n'ai pas le droit de mettre les vrais noms, l'avocate me l'a interdit, ni les vraies initiales. "Ce manuscrit présente de manière récurrente, un problème lié à la divulgation de la vie privée des proches de l'auteur, notamment celle de sa fille Léonore, mineure, de son ex-conjoint, Claude, de son père [qui entretenu avec elle - voir les longues descriptions en fin d'ouvrage - des rapports incestueux]. D'autres personnes voient également l'intimité de leur vie privée étalée au grand jour, avec force détails, notamment Marie-Christine Adrey, l'amante de l'auteur et "personnage" principal de l'ouvrage, la comédienne Nadine Casta, etc. (p. 41).

A defesa do uso do nome ganha o formato de um reclame, como fazia Zola, mas no corpo do romance, na voz da narradora-protagonista homônima. Ela não apenas se questiona como abordar o personagem retirado da vida 
real diante do leitor, como se trabalhasse num "laboratório da literatura" aberto ao público (BURGELIN, 2011, p.41). Angot expóe a "interdição" da advogada da editora. Ao expor as entranhas do processo, o reclame ganha ares de um libelo disfarçado de literatura. Vide o trecho no qual a advogada pontua, página a página, onde a literatura avança sobre os limites legais: é a tal tipo de documento que a narradora se reportará para denunciar o silêncio que "os outros" querem impor à sua escrita.

Au-delà du problème général, qui atteint l'ensemble du manuscrit, il faut relever les passages suivants qui révèlent un propos particulièrement imprudent. Elle ne veut pas que je l'appelle $X$. Ni son vrai nom, ni ses initiales. (...) Ni X, ni $M C A$, ni Marie-Christine Adrey, ni Aime CA. Atteinte à la vie privée d'autant plus intolérable que le refus de Marie-Christine Adrey d'être reconnue est souligné par l'auteur elle-même et que la révélation de son identité permet de la relier à l'ensemble de l'ouvrage. Ta cousine. NC, Nadine Casta, haine c'est, ce cinéma, ce théâtre, ce fric-là (...) Pour l'Ascension, lî̀le de Ré avec NC. Atteinte à la vie privée teintée, au surplus, de dénigrement (...) (p. 41-42).

Aqui se dá um paroxismo de mise en abyme, já que a voz da narradoraautora é evocada, copiada, reproduzida pelo advogado que a censura e entáo transformada em um monólogo interior. Trechos das páginas anteriores são aqui transcritos como excertos que deveriam ser amputados - sua simples presença prova a "vitória", digamos, de uma intenção literária. O livro diz o que não pode enquanto diz que não poderia dizê-lo e explica por que o faz. O centro do embate entre a escritora, sua literatura em sua especificidade, a defesa dessa literatura, aberta à diegese do romance, e a censura externa é, justamente, o nome próprio.

Como diz LAVOCAT (2016, edição e-book), "longe de ser uma 'zona de não-direito', a ficção é o lugar de uma negociação constante desse equilíbrio" - no caso, entre a proteçáo da vida privada e a liberdade de expressão, negociação que reflete o lugar histórico-cultural da separação ontológica entre fato e ficção e da (não) aceitação, pelo público e pela justiça, desse cruzar de fronteiras. $\mathrm{O}$ espaço do romance é justamente esse debate: direito à privacidade, de um lado, censura, de outro. E toda a prática vampiresca da autora que não reconhece limites e brada que enfrentará homens e leis, por quixotesca que seja, é atraente. Sobretudo após o jogo se instaurar com o leitor: "(Ça m’ennuie d'avoir changé les noms. Ça rend le livre moins bon. Mais je préfère, plutôt que de payer des dommages.)” (p. 144)

São verdadeiros os nomes e abreviaçóes que apareciam no excerto proibitivo do advogado (p. 41)? A frase acaba por incitar ao leitor (sobretudo se for um habitué da autoficção e do "sujet Angot") uma busca fora do romance, comparativa entre o discurso ficcional e o real, na Internet, nos 
jornais, em outros romances - sobretudo quando o romance desencadeia um embate judicial, que realimenta o interesse pelo estatuto discursivo do livro.

Em Quitter la ville, publicado em 2000, logo após o vendaval que foi L'Inceste (é esse vendaval que o livro conta), o contrário emana do texto. Sem eufemismos, Angot não só deixa claro que seu sucesso está atrelado à performance midiática, mas o mesmo processo que a narradora descreve no romance (a estratégia de divulgação posta em marcha pelo editor Jean-Marc Roberts para fazer de Angot a dama polêmica da autoficção), surge na voz dele:

J'ai fait lire en avril le manuscrit à une avocate et je me suis bien gardé de le dire à Christine. L'avocate m'envoie ses conclusions, je les envoie à Christine. Je savais qu'elle en ferait son miel, c'est ce qui s'est produit. J'aurais préféré qu'on puisse garder les vrais noms mais on aurait été sûrs de perdre le procès. Elle veut être célèbre, Christine, et j'ai tellement envie qu'elle le soit."

No trecho, pinçado de uma entrevista dada por Roberts a uma revista e trazido para o corpo do romance, fica evidente que Angot queria, sim, comprar a briga dos tribunais, ganhar uma tribuna como a de Zola, onde poderia defender a importância do nome real (e da história de vida real, sem rodeios) como sendo a verdadeira literatura. A editora, porém, disse não.

Os romances analisados mostram como Angot estabeleceu, por meio deles, seu lugar num tipo específico de jogo literário no qual qualquer crítica (moral, ética, legal) é imediatamente tragada para dentro da literatura. Se antes Angot usava os nomes dela e de sua família (ex-marido, filha, o pai que a molestara), atraindo críticas, a autora avançou sobre um terreno mais amplo: cada relação profissional ou caso amoroso, cada embate passa a ganhar espaço em seus romances. É por meio do uso do nome próprio real e de sua discussão no próprio corpo do romance que tal provocação ganha corpo.

Como explica FASSIN (2001, p. 1), há em Angot um "duplo jogo" literário: "l'écrivain devance la critique du sociologue, qu'il la rende redondante (tout est déjà dit dans l'œuvre), ou déplacée (l'œuvre ne dit pas ce qu'elle semble dire". Assim, a própria crítica sociológica, no âmbito da autoficção, torna-se parte integrante do sistema de produção-publicação-fruição organizado pelo campo. Com Angot, a análise do campo/ jogo é parte do próprio romance, sendo Quitter la ville o exemplo mais brutal.

Entretanto, Fassin náo dá a devida importância ao que faz de ambos os romances algo de teor ontologicamente vanguardista: os nomes reais. Verdade, ele diz que, sem o nome próprio, Angot perde sua força (p. 101). Porém, se a autoficção depende do nome próprio para provocar as regras do jogo (eu diria mais: perde sua defesa, seu paratexto ontológico), é porque o nome real é a peça central do jogo literário. Não só seu uso, mas, sobretudo, 
a defesa do uso, dentro e fora do romance. Diz Angot: "Je ne raconte pas MON histoire. Je ne raconte pas une HISTOIRE. Je ne débrouille pas MON affaire. Je ne lave pas MON linge sale. Mais le drap social" (2000, p. 172).

$\mathrm{O}$ uso do nome dos outros, para Fassin, se resume a uma espécie de "rupture avec le récit collectif" que vai do eu ao nós (p. 87). Mas esse "tecido social" que descreve Angot não é o mesmo de Zola. É um tecido que envolveu o corpo de Angot, é a tessitura entre sua vida pessoal e a de terceiros que ela expóe, retrabalhada narrativamente, mas guardando as marcas identificáveis de um universo de referências - das quais a mais forte é o nome. O que Fassin ignora é que o uso do nome próprio não apenas reforça o estatuto ficcional dúbio da autoficção, trazendo ao leitor certo prazer do texto ligado ao real vivido: ele se ergue em defesa de uma ontologia do literário, de sua potência como escrita e de sua aura de estética pura. É sobre o uso do nome próprio que se funda a obra e o discurso sobre a obra de Angot.

Do uso do nome autorizado à censura efetivada contra o nome de terceiros

Em Pourquoi le Brésil (2001), o uso do nome próprio de terceiros se esgarça. O livro trata de uma história de amor que impede a gestaçáo de uma história literária. A princípio, o tom da narrativa é o mesmo do livro anterior, e é tal volume que norteia a vida da narradora: ela está cansada, mas precisa ser forte ("tenir") nos próximos meses por causa da publicação do romance: ela fará suas leituras públicas, participará de programas de TV como Bouillon de Culture (p. 22) e dará uma entrevista a Pierre Louis Rozynès, jornalista de Livres Hebdo.

Existe um jornalista chamado Pierre Louis Rozynès, que trabalha em Livres Hebdo. E ele de fato escreveu o que a narradora transcreve. Angot (a personagem) e Rozynès passam a ter uma relação amorosa. É quando a narrativa que parecia a continuaçáo de Quitter la ville se transforma na história entre uma escritora em crise existencial e física e um jornalista que se mostrará louco. Ela contará a troca de telefonemas, a primeira noite, etc. Até que entra em ação a escritura: "Je lui disais que je n’arrivais pas à écrire parce qu'il ne m'arrivait plus rien. Il m'avait dit: comment tu peux dire ça, tu as une histoire d'amour" (p. 98).

A chave está dada. O homem que entrou na vida da narradora em crise de inspiraçáo de sua escrita (sempre baseada na vida dela em relação a quem a cerca) autoriza, incentiva a criação literária a partir da vida presente dividida. Que Angot tenha escrito um romance em que entrega de bandeja ao leitor a história de amor que teve com um homem cuja identidade (nome, profissão, história) é exposta mostra o quanto o nome real tem papel definitivo em sua 
literatura. Aqui, o nome serve para atestar o direito completo da literatura de dizer o real na voz da autora-protagonista homônima, incluindo o nome real de quem virou personagem. Não há embate, não há relutância, Pierre aceita. Chancela o procedimento.

Rendez-vous (2006) é o oposto disso. O livro traz novamente Pierre com seu nome real, mas os outros nomes, extraídos da realidade, foram modificados. O que permite tal análise entre romance e nome próprio real em Rendez-vous são os documentos contidos no Fonds Christine Angot, IMEC, depostos pela autora, por meio dos quais é possível traçar a genealogia do uso dos nomes ao longo da produção do romance e saber o porquê das mudanças. Há dois manuscritos ${ }^{5}$ com versóes da obra. Chamá-los-emos versão A e B. Quando comparada com a versão B e com o romance final, publicado, a A traz trechos significativos em relação à ediçãoo (ou mesmo de censura e autocensura).

$\mathrm{Na}$ versão $\mathrm{A}$, há o seguinte trecho: "Vous êtes au secrétariat de JL. Il habitait dans le troisième" (p. 3). Na versão B, ele vira: "Vous êtes au secrétariat de JL [a caneta: G.]. Il habitait dans le troisième [a caneta: sixième]" (pp. $3-4)^{6}$. As mudanças foram acatadas na versão final do romance publicado. A página 25 da versão $B$ é significativa de como funciona o processo de mudanças das referências depois que elas já cumpriram um primeiro papel de situar Angot em sua tessitura narrativa. As referências a nomes reais, assim como indicações geográficas que possam revelar identidades, são trocadas. Comparemos as duas versóes:

A: "J'aurais pu décrire la haute bourgeoisie, parisienne depuis des centaines d'années, originaire d'Alsace, tout, la maisons dans le Lubéron, j'avais vécu des scènes d'anthologie... (...) C'était un homme de pouvoir qui risquait de faire un procès, un ami de [laqui ela escreve a caneta: des gds patrons...] Fabius, de Bolloré, de Lagardere, de Douste-Blazy, [/]d'Helen Notable[/], de Louise Bougeois aussi, et avant de Warhol, de Nicky de Saint-Phalle de leur vivant, de tous les Pdg, Saint-Gobain, Carrefour, et les grands patrons de l'édition. La Banque mondiale, Renault, Peugeot" (p. 24).

B: "J'aurais pu décrire la haute bourgeoisie, parisienne depuis des centaines d'années, originaire d'Alsace [a caneta: Bordelais, Gironde, Bonzance], tout, la maisons dans le Lubéron [Var], j'avais vécu des scènes d'anthologie... (...) C'était un homme de pouvoir qui risquait de faire un procès, un ami de Fabius, de Bolloré, de Lagardere [Lang, de Perault, de Rockfeller, AllanMauve], de Douste-Blazy, d'Helen Notable, de Louise Bougeois [Fam D.]

5 Chamo aqui de "manuscritos" as versōes escritas no computador, impressas e anotadas a caneta.

$6 \mathrm{Na}$ versão A, há o seguinte trecho: "son appartement d'avant sur le quais de Béthune, la nuit il voyait passer les bateaux sur la Seine” (p. 20). Na versão B, tem-se: "son appartement d'avant sur le quais de Béthune [a caneta: d'Orléans], la nuit il voyait passer les bateaux sur la Seine” (p. 20). 
aussi, et avant de Warhol, de Nicky de Saint-Phalle de leur vivant, de tous les Pdg, Saint-Gobain, Carrefour [apenas riscado], et les grands patrons de l'édition. La Banque mondiale, Renault, Peugeot" (p. 25).

Outros trechos denotam o trabalho de procura de um nome que retrate o personagem oriundo do real ${ }^{7}$. Por exemplo, o mordomo. Na versão A, temse: "À propos de ce gardien, il m'avait dit: tu seras gentille avec Jacky, c'est quelqu'un d'important pour moi" (p. 73). Na versão B, temos: "À propos de ce gardien, il m'avait dit: tu seras gentille avec Tony [canto da página, a caneta: Francis, David, Jean-Louis, Fred, Robert, Antoine, Boris, etc], c'est quelqu'un d'important pour moi" (p. 73).

Por que Angot se debruça sobre a mudança dos nomes? Duas correspondências contidas no fundo dão ideia: por imposição dos editores e seus advogados, o que a narradora classificou de "cirurgia jurídica" em L'inceste. A primeira é um e-mail do escritório do advogado Emannuel Pierrat à editora Teresa Cremisi, da Flamarion, onde se lê:

\section{Ma Chère Teresa}

Je reviens vers vous à la suite de notre conversation de ce jour concernant le manuscrit de Christine Angot. Comme je vous l'a indiqué, il s'avère que plusieurs personnes citées dans ce manuscrit sont visés par de propos diffamatoires, injurieux ou portant attente à leur vie privée et sont donc susceptibles d'introduire des actions judiciaires sur ces fondements.

C'est pourquoi il convient, en premier lieu, de remplacer les noms et prénoms réels par des noms et prénoms ne permettant pas d'effectuer de rapprochement avec les personnes existantes.

A titre d'exemple, les initiales JL sont trop proches de JC. Il convient donc de remplacer JL par une autre initiale (par exemple E.).

De même, il est inutile de remplacer le prénom Jacky pour Tony, qui garde la même consonance que le prénom initial. Je vous suggère plutôt de remplacer Jacky pour un prénom tel que Pierre au Paul.

En tout état de cause les noms suivants doivent être modifiés: Laure, Simon, Jacky, Eric Elmosnino, Jim D., Jacky, Christine (page 38), Lisa (page 192) ainsi que les initiales JL.

En second lieu, il convient, dans la mesure du possible, de supprimer tout élément rendant les personnes susvisées aisément identifiables, certaines

$7 \mathrm{Na}$ versão A, temos "Mais sur cinq ou six ans, des gens différent, dans des villes différentes, m’avaient rapporté avec des anecdotes toutes différentes : ah, tu sais il y a un acteur qui t'adore : Eric Elmosnino [a caneta: Estenoza/]" (p. 40). Eric Elmosnino é ator conhecido. Na mesma versāo, lemos: "MarieChristine m'avait dit : il y a un acteur qui t’adore, Eric Estmosza (nome riscado, Estenoza) (p. 88). No romance, ele será Eric Estenoza. 
caractéristiques de leur vie privée ou encore le nom de leurs amis.

Par surcroît, l'identification du banquier ou d'Eric Elmosnino permet l'identification de leurs femmes. Or, la révélation de la liason de Christine Angot avec leurs maris porte gravement atteinte au droit au respect de la vie privée de celles-ci (Fonds Christine Angot, IMEC, grifos meus).

O e-mail descreve um serviço contratado pela editora a um escritório de advocacia especializado e descreve os passos para evitar um processo por atentado à vida privada e difamação. Tudo o que se refere aos nomes, lugares, cifras, etc., deveriam ser trocados ${ }^{8}$. Tal correspondência mostra como os advogados não percebem que é no enfrentamento (ético, estético e jurídico) que subjaz o específico da autoficção: é na relação com a referência identificável que paira o singular dessa literatura e no risco e no enfrentamento com a opinião pública e com a justiça que jaz seu caráter de vanguarda, de provocação estética.

Outro e-mail, do advogado George Keijman, representante do banqueiro Jean-Claude Meyer, a Teresa Cremisi, datada de 10 de julho de 2006, sugere novas mudanças no manuscrito. É aí que se confirma que é no banqueiro que se "baseia" Angot para construir o personagem JC-JL-G. E fica claro que o uso dos nomes próprios em Rendez-vous foram fruto de uma negociação longa com várias partes envolvidas.

\section{Chère Teresa}

Je poursuis ma tentative d'aboutir à un accord amiable, tentative purement amicale de ma part et que nous oublierons donc l'un et l'autre si nous ne parvenons pas au but. Voici la liste de modifications, par ordre de priorité décroissante, que Jean-Claude aimerait voir réaliser avec l'accord de Christine Angot bien entendu:

(...)

Les suppression les plus importantes sont celles de la page 12 car elles rendraient moins facile l'identification de Jean-Claude Meyer.

Il me semble que Christine Angot pourrait les accepter sans trop de difficultés pour les raisons suivantes:

\footnotetext{
8 Vide outro trecho do e-mail: “C'est ainsi que, concernant le banquier, les particularités suivantes doivent être modifiées afin que celui-ci, et plus particulièrement sa femme, ne soient pas identifiables: - "Il habitait dans le troisième" (há o numeral seis grafado em caneta sobre o termo troisième): changer l'arrondissement du domicile; - "Jouant au golf" (golf grafado em caneta): changer de sport; - La maison dans le Lubéron: le texte fait très fréquemment référence à cette maison dans le Lubéron. Il est impératif de modifier son emplacement géographique; (...) "la mention de noms des amis du banquier le rend identifiable ainsi que sa femme, je vous suggère donc de supprimer ces listes de noms d'amis ou de remplacer ces noms par d'autres noms d'artistes et de sociétés; (...) Concernant Pierre Rozynès, je vous invite à vérifier qu'il n'était pas impliqué dans une relation avec une autre femme au moment où la reprise des ses relations intimes avec l'auteur est mentionnée" (Fonds Christine Angot, IMEC, grifos meus).
} 
1/ Cela n'altère pas les qualités de son écriture, du moins me semble-t-il, mais elle seule peut en juger.

2/ Elle avait elle-même compris la nécessité de ne pas permettre l'identification de Jean-Claude, puisque non seulement elle l'appelle $\mathrm{G}$ mais elle a spontanément modifié plusieurs détails qui auraient permis de le reconnaître (par exemple le lieu où il habite, le lieu de sa maison de campagne...).

(...)

Par ailleurs, il va de soi que tout ce qui pourrait moins blesser Anne Claire Taittinger serait le bienvenu, et cela me ferait plaisir personnellement.

3/ Christine Angot connait bien le problème puisque dans son livre même, elle rappelle la lettre que Pierre Rozynès lui avait écrite avec les mêmes préoccupations.

J'aimerais pouvoir dire à Jean-Claude qu'il est possible d'en finir sur ces bases car une procédure judiciaire ne serait de l'intérêt de personne, quelle qu'en soit l'issue. (Fonds Christine Angot, IMEC, grifos meus).

Em resumo, todos os nomes de pessoas foram trocados segundo demandam as duas correspondências. Os nomes de locais, datas e outras referências foram parcialmente aceitos.

Quando o uso do nome de terceiros ganha os tribunais

No caso de Le Marché des Amants (2011), Angot conta seu affair com Bruno Beausier, alias Doc Gyneco. Os nomes reais são mantidos. No fim do livro, a narradora-protagonista passa a se relacionar com o amigo de Doc Gyneco, Charly Clovis (que existe na vida real com esse nome e hoje é marido de Angot). No romance, Angot cita o nome dos filhos de Clovis (Tafari, Kebra, p. 311). Daí a ex-mulher de Clovis, Elise Bidoit, iniciar um processo judicial, que terminou em acordo - Angot pagou uma multa e o caso se encerrou.

Da fixação pelo nome real: Les petits e a busca do nome ideal

No romance Les Petits (2011), o mais polêmico de Angot, justamente dada sua repercussão jurídica e midiática, ela volta a tratar da vida anterior de Clovis. Já nos detivemos sobre a repercussão judicial do caso9: o juiz condenou Angot. É interessante ver como Angot manipulou os nomes e apenas os nomes, a princípio para se livrar de um processo judicial. No fundo há duas caixas com ao menos 15 versões distintas de Les Petits. Um primeiro manuscrito parece encontrar sua unidade (versão A, caixa 19).

9 Vieira, Willian. Quando a justiça ganha da autofiç̧ão. Criação e Crítica, 2016. 
Ele começa assim:

La première fois que Charly a vu Elise, c'était dans le couloir de l'hôtel. (...) Elle était à l'hôtel avec sa fille, elle devait aller au Japon. Ils se sont rencontrés dans cet hôtel. Lui était de passage avec un groupe de reggae, les Ruffnegs, ils devaient faire des concerts à Paris. Elle allait partir au Japon, le père de Klotile devait y ouvrir des boutiques (versão A, p. 1, grifos meus).

Aqui, os nomes correspondem à realidade (segundo os autos do supracitado processo judicial). Charly, o pai, Elise, a mãe, Klotile ${ }^{10}$. Nessa versão ainda não existe a enquete do serviço social, nem a perda da guarda dos filhos. A impressão é que, nesse momento, Angot (a autora, real) está recém-chegando na vida de Charly. $\mathrm{O}$ que se percebe é que o texto parece vir de conversas com Charly, como se pode depreender a partir de dezenas de folhas repletas de anotações numa escrita rápida, de quem toma notas de uma conversa. As páginas são numeradas, o que demonstra uma ordem.

\section{Mariage}

Elise est mariée, elle est pas divorcée. Officiellement elle est mariée, divorce pas prononcé - la question n'est pas... on en a parlé, mais les termes "officiel..." Ça a pas été aussi loin que ça. C'était pas un acte, Elise a 1 papier US et le papier n'est pas officiel en Fce.

A la base je sais qu'on peut pas se marier (...) (p. 1)

Elise veut pas qu'il voit son père - parce qu'elle (...) de lui (p. 3)

J'aimais la vie que j'ai eu avec El.

Tafari - soja vanille, après lait d'amande

Nesta - lait d'amande

(...)

Os nomes reais migram das anotaçóes para as primeiras versóes do manuscrito e são depois paulatinamente substituídos. O que se depreende da comparação das anotaçóes com os manuscritos e o romance final é que o

10 Vide outros exemplos: "Elle était enceinte quand ils son arrivés. Kebra y est née. Ils laissent la Martinique, parce Elise ne sait pas conduire, et qu'elle n'est pas indépendante (p. 11); "Un jour, elle lui demande de tatouer son nom, Elise, sur son corps. Il lui dit non” (p. 17) “Tafari s'annonce. Ils vont aux échographies, Charly est heureux d'avoir un deuxième enfant, il n'y a qu'avec eux qu'il se sent vivant" (p. 38). "Le juge lui donne une convocation pour passer devant un tribunal en janvier. Ils l'interrogent sur Klotile uniquement. Il a agressé l'enfant de Mme Bidoit (p. 45). "Enfin, il parle pas de Salomon, Nesta, Tafari, Kébra, Klotile” (p. 51). 
método Angot parte sempre de uma entrevista-conversa com a pessoa próxima, onde ela toma notas em folhas de papel enumeradas: cada sequência conta a história de uma conversa-entrevista que depois será retrabalhada, editada, ganhando a forma narrativa do romance, sua voz, seu estilo direto - que muitas vezes parece soar natural e "verdadeiro", talvez por ter sido originado na coloquialidade da fala, da voz oralizada na entrevista. Daí por que os nomes das pessoas reais subsistam nas primeiras versóes.

No manuscrito $\mathrm{B}$, os nomes já são Hélène e Billy, mas os sobrenomes seguem como "Mme Bidoit" e de "M. Clovis". Na p. 81, a narração muda: a narradora, impessoal, onisciente, que sabe o que Hélène e Billy fazem e pensam, que alterna os pontos de vista, de repente transforma-se em primeira pessoa participante da ação:

On se rencontre. Il quitte Béa, il vient vivre avec moi. Il pense que je suis la femme avec qui il veut vivre sa vie, la femme qu'il aime. Il sort d'une histoire où on voulait s'approprier sa liberté (p. 81).

A impressão é que, a partir do momento em que Angot passa a narrar eventos dos quais fez parte, a narração ganha a primeira pessoa - por isso, ela é personagem e narradora ao mesmo tempo a partir daqui. O tom (frases curtas, em ordem direta, de vocabulário simples, como num eterno depoimento) é o mesmo. Na p. 86, há o nome da narradora, que aparece numa conversa entre Billy e seu filho: "Kebra tu reste avec Christine". Mais à frente surge o nome da filha de Angot: "Léonore est là" (p. 88). Na p. 99 surge um trecho do relatório do serviço social, onde constam os nomes reais. O enxerto é patente.

Na versão $C$, o manuscrito muda alguns nomes e tem vários trechos suprimidos em prol de uma prosa mais enxuta e direta. Vemos que a escolha dos nomes náo era definitiva. M. Clovis é aqui M. Larcher. M. Bidoit aqui é Mme. Bayen e terminará como Mme. Lucas ${ }^{11}$. Na versão $\mathrm{F}$, a última com mudanças onomásticas, pela primeira vez a página de rosto traz o título, a caneta, "Les petits". Há Billy, Hélène, Mary, Clara, Jérémie e, pela primeira vez, o sobrenome Lucas. Esses serão os nomes usados na versão publicada do romance.

O que interessa aqui é ver como Angot parte da história real a partir da entrevista e das anotaçóes para o manuscrito com os nomes reais e aos poucos vai mudando os nomes, ao mesmo tempo em que aprimora a estrutura narrativa (sem perder a relação de oralidade) e deixando marcas ao leitor sobre

11 Na versão D, os nomes já são outros. Na E, outras mudanças. Odylle vira Mary, Clara vira Sarah. O menino é Jeremie. Béa virou Chloé. Surge Maurice (p. 51). Mme. Bidoit ainda é Mme. Junot (p. 34), Hélène Junot. 
o que vem de fora (o itálico nos documentos, por exemplo). A quantidade de manuscritos mostra que o retrabalho é árduo e intenso, ainda que o material seja aparentemente extraído in natura da vida alheia e da sua própria. Tudo leva a crer que Angot só muda os nomes reais quando a estrutura da história já está montada e os personagens já refletem uma identidade formada. $\mathrm{O}$ nome, assim, garante, no processo de criação, esse suplemento de verdade atrelado ao real. Ele guarda a energia do vivido, do qual Angot só abre mão quando tem um manuscrito para enviar ao editor.

\section{A defesa ontológica do direito de usar nomes reais}

A partir da discussão desses seis romances a respeito do uso dos nomes próprios de terceiros, podemos tecer uma análise mais aprofundada sobre o que representa tal uso para a literatura de Angot. Em Quitter la ville, a narradora homônima dizia:

Il faut faire en sorte que le lecteur croie en la véracité de tout ça. Qu'il soit persuadé que la plus grande part s'est réellement passée, c'est le but essentiel de toute création littéraire. Convaincre le lecteur de l'authenticité de toutes nos inventions littéraires. La littérature n'a pas d'autre but. Le document est le moyen le plus sûr (p. 29, grifos meus).

E que documento maior existe que o nome real de uma pessoal real? Se Zola acreditou na potência de uma "literatura científica" que não inventasse seu material humano, Angot trilha caminho semelhante, na teoria e na prática. Em seu Usage de la vie (1998), texto escrito como peça de teatro e depois publicado como romance (a versão citada é de 1999), a autora faz uma espécie de defesa de sua literatura, como prática e como teoria.

On peut utiliser toute la vie dans l'écrit heureusement. Tout, on peut tout dire, tout. Dans l'écrit. Que son enfant, on voudrait la voir morte. Que les Juifs, on leur crache dessus. Tout. Quand je me retrouve avec cette liberté totale devant la page, je m’aperçois qu'il n'y a rien à dire. (1999, pp. 17-18).

Como se a liberdade completa se tornasse uma liberdade negativa, uma leveza insustentável, o autor precisa da oposição, da interdição, para se pronunciar. Sua literatura é necessariamente dialógica, um diálogo com o limite, com um discurso que se interpóe entre sua vida e o papel $^{12}$. Processada por

12 "J'ai toujours été incapable d'inventer. Il n'y aurait pourtant rien de plus facile que de confronter les personnages A, B et C. Des les placer dans le cadre d'une réalité théâtrale, de les habiller de vêtements multicolores pour que ça ressemble à la réalité (...). Une norme de la société, dans la littérature qu'estce que ça vient faire? Être incapable d'inventer n'est pas de l'impuissance, c'est un principe. Et je me moque du public qui croit aux inventions plus qu’à tout" (1999, p. 18, grifos meus). 
Les petits por ter exposto a vida privada de Elise Bidoit e seus filhos, Angot chamou para si a defesa de certo tipo de procedimento de criação literária. Como disse seu advogado na corte, como Zola, Angot descreve a realidade. Ela não se baseia, ela escreve. Angot não inventa, ela reorganiza os materiais brutos do real.

Em um ensaio, Angot defende seu direito inalienável de escrever:

Si on ne peu pas dire ce qui est, quel est l'intérêt? Vivre des choses, et ne pas pouvoir dire ce qu'elles sont? Que ce ne soit pas possible? Que ce soit interdit, réprimandé, condamné? Perdre des procès parce qu'on a dit c'est qui est? Parce qu'on a fait un travail d'objectivité, de perception, de réflexion, pour aller au-delà des apparences, et pour dire ce qui est, pour décrypter le visible? (2011b, p. 31, grifos meus).

$\mathrm{Na}$ defesa de certo naturalismo da vivência subjetiva - que flerta com o testemunho, mantendo distância do compromisso ético do discurso de verdade -, Angot defende um inalienável direito de escrever a vida vivida de forma "objetiva".

Donc voilà, inlassablement, et jusqu'au bout, $\mathrm{j}$ 'ai ça à faire : trouver la forme du réel, les mots du réel, les mots de ce qui se vit. (...) Il faut, et je dis bien « il faut", souvent les gens ne comprennent pas ce « il faut ", il faut trouver, et montrer, une forme de la vie qui s'oppose à une vie de forme. Voilà pourquoi c'est subversif la littérature, ça casse le moule. (...) C'est un combat à deux, un combat par contraste, mais l'adversaire ne s'exprime pas. Il s'est déjà exprimé, il a déjà nui, et il reprendra après (2011b, p. 33, grifos meus. ).

Um naturalismo do conteúdo, e não apenas da forma: Angot dá à noção de "real" uma substância ontológica inatacável, aquela advinda de um misto de idealismo sem limites (é preciso o combate, é dizer o real interdito) com o martírio da obrigação da escrita. Fiel ao contrato com a realidade, o escritor deve escrever a todo custo a vida que viveu, a despeito dos outros. Em seu discurso crítico-teórico (entrevistas, artigos acadêmicos e nos próprios romances, via sua narradora que diz eu e se chama Christine Angot), a autora estabelece um arcabouço ontológico que embasa sua prática literária. Como diz DUBOIS (2011, p. 19), para Angot, o objetivo seria se colocar em jogo (seu corpo, seu nome, sua vida). Assim, "Il s'agit de risquer son existence en la rendant publique et en la tenant pour espace de transit des relations avec autrui”. Inaugura-se, assim, uma prática de provocação sistemática que "pretende escapar do aparelho literário" normalizado (idem). 
C'est pourquoi encore il recourra à divers procédés de provocation. Le plus voyant et le plus violent d'entre eux consistant pour Angot à citer nommément les " acteurs " de sa vie et jusqu’à le faire en termes désobligeants ou compromettants (2011, p. 19. grifos meus).

Em síntese, o lugar do nome real na autoficção de Angot se constitui como objeto de uma pureza e uma especificidade das quais se investe o “jogador profissional" da literatura no afã de tornar-se especialista numa frente específica do jogo literário. $\mathrm{Na}$ esteira de Lahire, conclui-se que bater o pé em defesa do direito de usar qualquer material biográfico-real em nome de um direito ontológico da literatura de dizer esse real garante esse lugar de enunciação: defender uma prática literária é uma estratégia para atrair para si as regras do jogo, pervertendo-as. Angot se torna a vanguardista que queria ser, fixando-se como senhora de um jogo: a "vampira da autoficção", como foi apelidada pela imprensa. $\mathrm{O}$ processo judicial apenas culmina o esforço de constituir uma imagem de purista do jogo, de profissional a serviço de uma causa, causa essa que reflete a imagem da especificidade do escritor. Angot defende uma ideia de literatura que não aceita o peso da lei.

Construir uma imagem, ou "construir um autor", poderíamos dizer, na esteira de DIAS (2000), é cabal para se constituir como "escritor imaginário", ou seja, "escolher uma identidade própria, enraizada em sua fantasmática pessoal" (p. 61) seria fundamental para se "inscrever no imaginário social" (idem). Assim, uma série de gestos e decisóes precisam ser trabalhados para encontrar o "domicílio simbólico" que garanta a "produção de si" (idem) dando ao autor sua cara e sua causa. Esse processo de "auto-engendramento", tão mais forte no romantismo que antes, diz Dias, que "propóe ao consumo mitológico um personagem sedutor" (p. 61), passaria por peritextos e epitextos pelos quais o autor determinaria "uma postura, própria para funcionar como uma espécie de 'indicativo' de sua obra” (p. 62).

$\mathrm{O}$ caso de Angot é ainda mais complexo. Basta uma pesquisa no Google para se identificar a veracidade de vestígios onomásticos, a existência de documentos oficiais trazidos para o romance, o impacto de notícias com rescaldos de embates judiciais. O que Dias chama de "estetização da vida" (p. 63) ganha um outro tônus quando se sai de Byron, o poeta maldito que vivia no real o que seus personagens faziam na ficção, para Angot, onde a autora não só vive o que escreve, mas escreve em seu nome, mantém o nome dos outros e defende o uso dos nomes como centro nevrálgico da importância específica da literatura atual.

Claro, recentemente, Angot assumiu um posicionamento que relativa tal questão. Em entrevista a Forcolin (2012), ela diz: 
Aujourd'hui, je n'ai pas envie d'employer les noms réels, tout simplement parce que je n'ai pas envie d'avoir des histoires judiciaires. Donc, si ce qui fait fonctionner le texte c'est un nom réel, c'est bien, mais si le nom réel met en danger le texte dans sa vie future parce qu'il va être attaqué, ce n'est pas bien. La seule chose qui m'intéresse, c'est la survie du texte (p. 15-16, grifos meus).

Tal discurso pode refletir uma mudança no projeto literário de Angot, ou mostrar apenas uma mudança de "estratégia". Se Angot, profissional de seu metiê, do jogo literário no qual se firmou como ícone, estrategista que escreve a partir das entranhas do jogo, revê seu discurso sobre o nome próprio real na literatura - uso que permitiu que ela galvanizasse uma imagem própria, constituindo-se, como diria Dias, como "escritora imaginária" - é porque há algo no horizonte de sua prática que se ensaia em sua teoria. Resta esperar a próxima rentrée.

\section{Referências}

ANGOT, Christine. Les petits. Paris: Flammarion, 2011.

ANGOT, Christine. Pourquoi le Brésil. Paris: Stock, 2002.

ANGOT, Christine. L'inceste. Paris: Stock, 1999.

ANGOT, Christine. Sujet Angot. Paris: Fayard, 1998.

ANGOT, Christine. Quitter la ville. Paris: Stock, 2002.

ANGOT, Christine. Rendez-vous. Paris: Flammarion, 2006.

ANGOT, Christine. Usage de la vie. Paris: Fayard, 1998.

ANGOT, Christine. "Acte biographique": In: FOREST, Philippe (dir.), Je \& Moi, Nrf, n598, octobre 2011b.

BECKER, Colette. Zola, écrivain-homme d'affaires. Revue d'Histoire Littéraire de la France, v. 107, 2007, p. 825-833.

BURGELIN, Claude, GRELL, Isabelle. Autofiction(s), actes du colloque de Cerisyla-Salle. Lyon: PUL, 2010. 
DIAS, José-Luis. Le poete comme roman. In: LAVIALLE, Nathalie, PUECH, JeanBenoit (dir). L'auteur comme oeuvre: L'auteur, ses masques, son personnage, sa légende. Orléans: Presses Universitaires d'Orléans, 2000.

FASSIN, Éric. Le double 'je' de Christine Angot : sociologie du pacte littéraire . Sociétés \& Représentations, v. 11, n. 1, 2001, p. 143-166.

FORCOLIN, Francesca. Est-ce que je peux vous chanter une chanson? Entrevista com Christine Angot, 2012. Disponível em: http://www.christineangot.com/sites/ default/files/Interview.pdf

GIRAUD, Frédérique. La double croyance dans le jeu littéraire d'Émile Zola. COnTEXTES [digital], n. 9, 2011, acessado em 28 de agosto de 2011.

LAHIRE, Bernard. La condition littéraire: la double vie des écrivains. Paris: Éditions La Découverte, 2006.

LAVOCAT, Françoise. Fait et fiction. Pour une frontière. Paris: Seuil, Collection Poétique, 2016.

VIEIRA, Willian. Quando a justiça ganha (d)a (autoficção). Revista Criação \& Crítica, São Paulo, n. 17, p. 146-166, dec. 2016.

ZOLA, Émile. Correspondance: Nouvelle édition augmentée. Anversa Éditions, 2014, e-book.

Willian Vieira é doutor em Letras Modernas pela Universidade de São Paulo, com foco em literatura francesa contemporânea. Pesquisa escritas de si e autoficção e as relaçóes entre literatura e imprensa.

E-mail: vieira.will@gmail.com 